\title{
A BONITEZA DOS ENCONTROS: CAMINHOS QUE SE CRUZAM NAS ESCUTAS, CARTAS E NA FORMAÇÃO INVENTIVA DE PROFESSORES
}

\begin{abstract}
RESENHA: DIAS, Rosimeri de Oliveira (Org.); RODRIGUES, Heliana de Barros Conde (Org.). Escritas de Si: escutas, cartas e formação inventiva de professores entre universidade e escola básica. 1. ed. Rio de Janeiro: Lamparina, v. 1, 2019. 256 p.
\end{abstract}

Resumo: A experiência dos caminhos nos traz memórias, reflexões sobre a vida e nossos fazimentos enquanto professores, pesquisadores e estudantes, e é através dos encontros por esses caminhos que aprendemos os sentidos das coisas. O livro "Escritas de Si: escutas, cartas e formação inventiva de professores entre universidade e escola básica", se configura como uma obra resultados dos encontros de diferentes professores, pesquisadores e estudantes, que cruzam seus caminhos na luta por articular dispositivos que funcionem a favor de mudanças na formação de professores. Estas cartas nos colocam em posição de reflexão e perspectiva em assumir um lugar de fala no processo educacional. Repensar a formação inventiva de professores, insistir na resistência da palavra, na importância dos caminhos que levam as práticas são marcas deste livro, que mais do que textos, traz almas em forma de letras.

Palavras chave: formação inventiva de professores; cartografia; estética; produção de subjetividade; escrita.

\section{THE BEAUTY OF ENCOUNTERS: PATHS THAT CROSS BY LISTENING, LETTERS AND TEACHERS INVENTIVE FORMATION}

\begin{abstract}
The experience of the paths brings us memories, reflections on life and our doings as teachers, researchers and students, and it is through the encounters by these paths that we learn the meanings of things. The book Escritos de Si: escutas, cartas e formação inventive de professores entre universidade e escolabásica, is configured as a work results of the meetings of different teachers, researchers and students, who cross their paths in the struggle to articulate devices that work in favor of changes in teacher education. These letters put us in a position of reflection and perspective in assuming a place of speech in the educational process. Rethinking the inventive formation of teachers, insisting on the resistance of the word, on the importance of the paths that lead practices are marks of this book, which more than texts, brings souls in the form of letters.
\end{abstract}

Keywords: teachers inventive formation; cartography; aesthetics; production of subjectivity; Writing

Toda trajetória traz consigo desafios, caminhar exige escolhas, decisões e enfrentamentos. Nesta resenha optei por caminhar de forma distinta ao estabelecido pelos cânones acadêmicos, fazer uma escrita outra que se encontre com os caminhos escolhidos pelos autores que compõem a obra. Nos tempos obscuros em que nos encontramos, poucos autores são tão essenciais quanto Michel Foucault: e o livro, Escritas de 
si: escutas, cartas e formação inventiva de professores entre universidade e escola básica, organizado pelas professoras Rosimeri de Oliveira Dias e Heliana de Barros Conde Rodrigues mostra isso de forma memorável. Dirijo-me a Rosimeri pelo primeiro nome, quando as estruturas acadêmicas estabelecem que deveria chamá-la, formalmente, de Dias , e o faço pois os nossos caminhos se encontraram no meu processo de formação no curso de mestrado em Educação - Processos Formativos e Desigualdades Sociais - da Faculdade de Formação de Professores da UERJ, logo, deixou de ser apenas Dias e passou a ser a minha professora Rosimeri.

O livro consta de dezessete seções compostas por textos que retratam escutas, cartas, um conjunto de concepções, tentativas, assim como esboços e práticas empreendidas pelos autores no processo de formação em contextura com escolas da educação básica. Os textos apresentam tons bastante variados, desde mais descritivos até aqueles, mais emocionados, mas todos nos tocam, nos fazem pensar sobre os nossos próprios caminhos e processos formativos enquanto professores, estudantes e pesquisadores. As diversas escritas se aproximam de algo tão latente em cada um de nós, fica visível que não é simplesmente um livro com escritas, são escritas que se tornam corpos, que se entrelaçam com as histórias dos próprios autores. Segundo Foucault:

O papel da escrita é constituir, com tudo o que a leitura constitui, um "corpo" (quiaquidlectionecolllectan est, stills redigat in corpus ) e, este corpo, há que entende-lo não como um corpo de doutrina, mas sim-de acordo com a metáfora tantas vezes evocada da digestão - como próprio corpo daquele que, ao transcrever as suas leituras, se apossou delas e fez sua a respectiva verdade: a escrita transforma a coisa vista ou ouvida "em forçase em sangue" (in vires, in sanguinem) elas transformam-se no próprio escritor, num princípio de ação racional. (FOUCAULT, 1992, p.133).

E esses corpos que se tecem aos caminhos percorridos por cada autor, se entrelaçam as memórias que de forma criativa fecundam uma escrita inventiva. $\mathrm{O}$ livro reflete, portanto uma prática de liberdade textual que mantém um intercâmbio entre o que é narrado, o sujeito escritor e o leitor, de forma que as memórias negociam com as experiências vividas de cada um, construindo assim um corpo que suscita movimentos de saída de si, devires inusitados e atualizações de novas virtualidades das subjetividades. O outro, em questão, se apresenta como mediador indispensável entre a prática de si e o objeto dessa prática que é o eu. Logo, a prática de si só alcança o eu (que é por ela visado) por meio do outro, através de um processo interativo.

Mais do que um virar de páginas, cada texto do livro nos remete a um convite a trilhar os caminhos percorridos por autores que se aventuram a escrita que retrata uma aposta ética, estética e política. Dessa forma, estes corpos nos sugerem um percurso no qual o si e o mundo encontram-se em um processo de transformação permanente. E, nesse contexto, os processos de subjetivação e objetivação são coemergentes a uma escrita de si. 
A escrita de si, como uma prática de si, é um contraveneno para essa falta de memória e para esse vaguear da vontade. A escrita de si é um dispositivo para enfrentar a multiplicidade, a pluralidade de imagens e as representações existentes no mundo exterior a nós mesmos. A escrita de si possibilita a rememoração do que merece ser rememorado e permite que a vontade não se disperse. A vontade tem uma única e permanente meta. O que se deve sempre querer, segundo os gregos, é o governo de si. (DIAS, 2019, p.23)

O entrelaçar dessas trajetórias individuais nos levam a um encontro de caminhos que nos afasta, tão necessariamente, da stultitia. Para Lima (2013).

O stultus é aquele que não quer, não quer a si mesmo, não quer o eu; é aquele cuja vontade não está dirigida para o objeto - o próprio eu. A forma para sair da stutitia é, portanto, fazer com que o indivíduo queira o eu, queira a si mesmo. Como o stultus não quer cuidar de si, para sair da stutitia (que se define por esta não-relação consigo) é necessário o outro.(LIMA, 2013, p.02)

Este objeto "eu" para ser constituído, só pode fazê-lo interposto ao outro. O indivíduo frente a esse outro não configura um mero receptor de saberes, como aquele que sai da ignorância, mas de certa forma recebe uma ação que incide sobre o modo de ser do sujeito. Da mesma forma, Escritas de si não configura um manual de instruções que visa traçar uma receita de fazeres, mas sim, escritas como uma prática de si que nos auxiliam a pensar, fazer e construir uma formação na perspectiva da invenção.

Pesquisar- pensar - fazer- escrever educação numa concepção de formação inventiva nos faz experimentar novas trajetórias que se desenham num olhar atento ao pensar formação, pensar com os outros.

Portanto, a partir da complexidade desse processo de leitura, reconstrução e fazimentos, numa concepção de educação que emerge de uma compreensão crítica da sociedade, pautamos nosso caminhar numa perspectiva de ações transformadoras que vinculam-se a um projeto democrático e político que visam questionar e enfrentar as narrativas egocêntricas que polarizaram as classes populares.

E é essa prática de liberdade de escritas outras que fazem de Escritas de si, uma carta que nos convida a repensar as estruturas socais e como o processo de formação basilado numa identidade inventiva, nos possibilita vislumbrar possibilidades de romper com as estruturas pré estabelecidas.

Este livro, fruto de trabalhos ligados a educação básica retrata, para além das concepções formais, caminhos de diferentes professores, pesquisadores e estudantes que têm em comum a luta por requerer dispositivos que se fundamentam e corroboram a favor de novos percursos na formação de professores.

Cada corpo que compõe este livro insiste na resistência da palavra que nos faz contestar os quadros $^{\text {ii }}$ que buscam nos isolar, separar, moldar de forma pré estabelecida, quadrada, mecânica. A cada carta, um convite a pensar e instigar-se a um encontro com práticas, sujeitos, objetos e paisagens outras que nos possibilitam enxergar formas outras de fazer escola e formação. 
Como todo trajeto, cada paisagem toca cada indivíduo de forma única e imensurável, que passa ao trilhar dos movimentos a fazer parte, mesmo que momentaneamente, da esfera constitutiva daquele espaço, daquelas memórias. Por isso escrever-pensar-refletir sobre um livro que representa para além de uma história a ser contada, um emaranhado de vivências que se cruzam e se fortalecem frente a tempos obscuros, nos faz insistir numa escrita outra, que se dá também, aqui nesta resenha.

Ouso aqui abrir possibilidades outras para afirmar a importância de tal obra em tempos em que pensar e fazer educação tornou-se sinônimo de resistir e a luz de uma sociedade que encontra-se vendada pelas forças da alienação, tornou-se uma possibilidade de construção coletiva de micropolíticas que enveredam pela busca da redemocratização dos espaços. As verdades preestabelecidas pela sociedade moderna nos remetem a Nietzsche (2008) quando o mesmo atiça:

Que transposições arbitrárias! A que distância voamos além do cânone da certeza! [...] Acreditamos saber algo das coisas mesmas se falamos de árvores, cores, neve e flores, e, no entanto, não possuímos nada mais do que metáforas das coisas, que de nenhum modo correspondem às entidades de origem. [...] As verdades são ilusões, das quais se esqueceu que o são, metáforas que se tornaram gastas e sem força sensível, moedas que perderam sua efígie e agora só entram em consideração como metal, não mais como moedas. (p. 55-56)

Portanto, o caráter arbitrário da linguagem confere também ao conhecimento, e por conseguinte a produção da verdade um caráter arbitrário. E esta produção arbitrária que se estende, particularmente, a cultura ocidental moderna, nos remete ao ato do "esquecimento" do processo linguístico de valoração de valores. E esta omissão do processo arbitrário de valoração e definição do verdadeiro e do falso que se perpetua nas entrelinhas da sociedade, acabam por conceber a esta verdade ilusória um status de certeza.

Foucault (1999) complementa:

O conhecimento é sempre uma certa relação estratégica em que o homem se encontra situado. É essa relação estratégica que vai definir o efeito de conhecimento e por isso seria totalmente contraditório imaginar um conhecimento que não fosse em sua natureza obrigatoriamente parcial, oblíquo, perspectivo. $\mathrm{O}$ caráter perspectivo do conhecimento não deriva da natureza humana, mas sempre do caráter polêmico e estratégico do conhecimento. Pode-se falar do caráter perspectivo do conhecimento porque há batalha e porque o conhecimento é o efeito dessa batalha. (p. 25)

No entendimento de Foucault, o conhecimento numa perspectiva do embate produziria, em tom mais preciso, os efeitos de verdade. Este, por sua natureza circunstancial, tornar se objeto privilegiado de problematização por parte dos sujeitos.

Problematizar - questionar - refletir sobre o conhecimento e a produção das verdades num período onde o flerte com o autoritarismo se escancara pelas janelas e sacadas ao longo do caminho, que o fazem 
ser, a cada dia mais tenso, nos faz reportar ao papel as múltiplas relações de poder nas quais os homens se encontram. E estas articulações concedem ao conhecimento uma implicação política. E a produção da escrita inventiva, em seu caráter reflexivo nos aponta para um embate de rompimento com as estruturas preestabelecidas de forma a pensar possibilidades outras de fazer - pensar- pesquisar educação.

Outrossim, estas cartas precisam ser lidas pois falam de vida, falam de política, não como a pensada num país onde a escola tornou-se sem partido , onde os gêneros se tornaram ideologias, onde as muitas verdades configuram instrumento de poder e repressão, Escritas de si, nos convoca a refletir sobre práticas que contribuem com o campo das políticas de educação que versam sobre a transversalidade em busca da resistência a estas amarras impostas pelas forças hegemônicas que tentam se consolidar .

Estes professores - pesquisadores - alunos, assim com Foucault, nos privilegiam uma leitura que corrobora para o entendimento de que crítica e crise se configuram como fenômenos modernos indissociáveis e nos possibilita enxergar o privilégio desse momento de crise para refletir criticamente a respeito do próprio processo educativo.

As cartas que compõem este livro, objeto desta resenha, falam de resistência, de formação inventiva, de vidas e caminhos e falam de educação. Não e também de educação, falam de educação pois educar exige resistir, exige vida, exige caminhar, apesar das pedras. Escritas de si se faz necessário pois fala de caminhos, e esses, os caminhos nos faz lembrar da coragem necessária para percorrer trajetórias outras, dentro e fora de nós.

\section{Referências}

DIAS, Rosimeri de Oliveira (Org.); RODRIGUES, Heliana de Barros Conde (Org.). Escritas de Si: escutas, cartas e formação inventiva de professores entre universidade e escola básica. 1. ed. Rio de Janeiro: Lamparina, v. 1, 2019. 256 p.

FOUCAULT, Michel. A verdade e as formas jurídicas. 2. ed. Rio de Janeiro: NAU, 1999a.

LIMA, J. A. Por uma análise de conteúdo mais fiável. Revista portuguesa de Pedagogia, 47(1), p. 7-29. Doi: 10.14195/1647-8614_47-1_1.2013.

NIETZSCHE, Friedrich. Sobre verdade e mentira. Organização e tradução de Fernando de Moraes Barros. São Paulo: Hedra, 2008.

SALES, M. (2016). Foucault e os dispositivos. IX Jornadas de Sociología de la UNLP, 5 al 7 de diciembre de 2016, Ensenada, Argentina. En Memoria Académica. Disponível em: http://www.memoria.fahce.unlp.edu.ar/trab_eventos/ev.9260/ev.9260.pdf 
Recebido em: 30/04/2020.

Aceito em: 03/08/2020.

Notas

i Mestrado em Educação, Processos Formativos e Desigualdades Sociais (UERJ/FFP). Especialista em Direito Educacional(UCB). Professor da Universidade de Vassouras. Professor da Rede Pública Municipal de Ensino de Maricá. Membro da Associação Brasileira de Direito Educacional (ABRADE). E-mail: projetos.edu.marica@gmail.com Maricá, Rio de Janeiro. ORCID: https://orcid.org/0000-0002-9343-139X

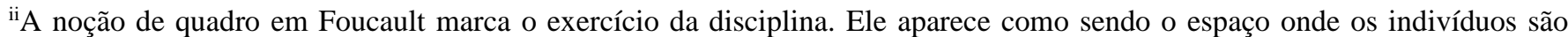
distribuídos tendo em vista a disciplina. Para mais detalhes ver Sales (2016). 